\title{
Improving the Water Oxidation Efficiency with a Light-Induced Electric Field in Nanograting Photoanodes
}

Wenrong Wang, ${ }^{\dagger \neq, \#}$ Beidou Guo, ${ }^{\ddagger, \S, \#}$ Haitao Dai, ${ }^{\prime \prime}$ Chang Zhao, ${ }^{\ddagger}$, Guancai Xie, ${ }^{\ddagger}$, Renping Ma, ${ }^{\ddagger}$ Muhammad Zain Akram, ${ }^{\ddagger}, \S$ Hangyong Shan, ${ }^{\perp}$ Congzhong Cai, ${ }^{\dagger}$ Zheyu Fang, ${ }^{*, \perp}$ and Jian Ru Gong ${ }^{*}, ;, \$$

${ }^{\dagger}$ State Key Laboratory of Coal Mine Disaster Dynamics and Control, Department of Applied Physics, Chongqing University, Chongqing 400044, China

${ }^{\ddagger}$ CAS Center for Excellence in Nanoscience, Chinese Academy of Sciences (CAS) Key Laboratory of Nanosystem and Hierarchy Fabrication, National Center for Nanoscience and Technology, Beijing 100190, China

${ }^{\S}$ University of CAS, Beijing 100049, China

"Tianjin Key Laboratory of Low Dimensional Materials Physics and Preparing Technology, School of Science, Tianjin University, Tianjin 300072, China

${ }^{\perp}$ School of Physics, State Key Lab for Mesoscopic Physics, Academy for Advanced Interdisciplinary Studies, Collaborative Innovation Center of Quantum Matter, and Nano-optoelectronics Frontier Center of Ministry of Education, Peking University, Beijing 100871, China 


\section{Experimental Section}

\section{Preparation of Nanograting Photoanodes}

1. Synthesis of PS microspheres.

Polystyrene (PS) microspheres were prepared by emulsion polymerization as reported in a previous study. ${ }^{61}$ Monodisperse PS dispersions were prepared using sodium lauryl sulfate (SDS) (AR), potassium persulfate (AR), and ethanol (AR) as emulsifier, initiator, and dispersion medium, respectively. Known quantities of sodium lauryl sulfate and potassium persulfate were dissolved in aqueous alcohol in a $250 \mathrm{ml}$ three-neck flask. A certain amount of styrene $(\mathrm{CP}>99 \%)$, previously washed with $10 \%$ sodium hydroxide solution in a separating funnel three times to remove anti-polymerizer, was then added in nitrogen atmosphere rapid stirring, and the emulsion was heated to $70^{\circ} \mathrm{C}$ and allowed to polymerize for $12 \mathrm{~h}$. After the reaction, the mixed solution was centrifuged and the solid sample was collected and dried at $50^{\circ} \mathrm{C}$ for $24 \mathrm{~h}$.

2. Preparation of PS microsphere monolayer.

A monolayer of PS microspheres was prepared by the interface method. Briefly, $5 \mathrm{wt} \%$ PS microsphere dispersion in a mixture of deionized water and absolute ethanol $(\mathrm{v} / \mathrm{v}$, 1:1) along with a tilted silicon piece, was slowly added to deionized water in a $15 \mathrm{~cm}$ diameter glass petri dish, then $30 \mu \mathrm{L}$ of $2 \%$ SDS solution was added. After $6 \mathrm{~h}$, a hydrophilic $\mathrm{SiO}_{2}$ substrate was immersed in the solution and slowly pulled out of liquid surface to form 2D monolayer of colloidal crystals PS microspheres. The PS microspheres with different diameters $(440,600$, and $1000 \mathrm{~nm})$ were used in three different monolayer preparation.

3. Etching $\mathrm{SiO}_{2}$ with PS microspheres as shadow mask.

$\mathrm{SiO}_{2} \mathrm{FC}$ nanogratings were fabricated by RIE. The RIE process was performed using a mixture of $\mathrm{Ar}$ and $\mathrm{CF}_{4}$ as the processing gas at the total flow rate of $50 \mathrm{sccm}$, chamber pressure of $0.4 \mathrm{~Pa}$, and RF power of $300 \mathrm{~W}$. Etching time was varied from 120 to 300 s. For the fabrication of non-close-packed $\mathrm{SiO}_{2} \mathrm{FC}$ nanogratings, the PS microspheres were first etched by $\mathrm{O}_{2}$.

4. Fabrication of ITO/Au/ $\alpha-\mathrm{Fe}_{2} \mathrm{O}_{3} \mathrm{FC}$ nanogratings.

To improve adhesion of the Au layer, a $150 \mathrm{~nm}$ ITO adhesion layer was first deposited by magnetic sputtering on the $\mathrm{SiO}_{2} \mathrm{FC}$. The Au film with the thickness of $100 \mathrm{~nm}$ was then deposited on the $\mathrm{SiO}_{2} / \mathrm{ITOFC}$ by thermal evaporation. Finally, the Fe film with a certain thickness was magnetically sputtered on the $\mathrm{SiO}_{2} / \mathrm{ITO} / \mathrm{Au}$ FC. 
After annealing at $600{ }^{\circ} \mathrm{C}$ for $4 \mathrm{~h}, \mathrm{SiO}_{2} / \mathrm{ITO} / \mathrm{Au} / \alpha-\mathrm{Fe}_{2} \mathrm{O}_{3} \mathrm{FC}$ nanogratings were successfully obtained.

\section{Characterization of samples}

X-ray diffraction (XRD) patterns were recorded using X'pert Powder diffractometer with an operating voltage of $40 \mathrm{kV}$ and $40 \mathrm{~mA}$ current, to elucidate the crystal structure of the prepared thin-film photoanodes; grazing incidence XRD (GI-XRD) mode was adopted to increase the signal-to-noise ratio. The micromorphology of the photoanodes was examined by a Hitachi S-4800 field emission scanning electron microscope (FE-SEM) at the accelerating voltage of $10 \mathrm{kV}$. Ultraviolet-visible (UV-Vis) transmittance and reflectance spectra were recorded using a UV-Vis spectrophotometer (UV-2600) equipped with an external diffuse reflectance accessory (DRA-2500), and the absorptance (A) was calculated using the formula A=1-T-R, where $\mathrm{T}$ is the total transmittance and $\mathrm{R}$ is the total reflectance.

\section{Photoelectrochemical measurements}

Photoelectrochemical measurements were carried out using an electrochemical workstation (ZahnerZennium, Germany) in a typical three-electrode configuration with the prepared photoanode as the working electrode, a Pt foil as the counter electrode, a saturated $\mathrm{Ag} / \mathrm{AgCl}$ electrode (SCE) as the reference electrode, and $1 \mathrm{M}$ $\mathrm{NaOH}(\mathrm{pH}=13.6)$ aqueous solution as the electrolyte. Samples with geometrical area of $0.636 \mathrm{~cm}^{2}$ were irradiated by a $150 \mathrm{~W}$ Xenon lamp (Crowntech. Inc., CT-XE-150) with the light intensity of $\sim 450 \mathrm{~mW} \mathrm{~cm}^{-2}$. All the measurements were performed with the sample irradiated from the electrolyte side and the angle between the incident light and the electrode was $90^{\circ}$. The photocurrent density versus applied potential (J-V) plots of the photoanodes were traced at the scan speed of $37 \mathrm{mV} \mathrm{s}^{-1}$ in the voltage range between -400 and $600 \mathrm{mV}$ versus SCE. To facilitate comparison between different samples, the measured photocurrent was normalized to the sample's macroscopic area to obtain the photocurrent density (in units of $\mathrm{mA} \mathrm{cm}$ ); the photocurrent started to rise at the onset potential.

A Si photodiode with known IPCE was used to calculate the IPCE values of the $\alpha-\mathrm{Fe}_{2} \mathrm{O}_{3}$ photoanodes, and a source meter (Keithley 2400) was used to measure the photocurrents of the Si photodiode and the photoanodes (here the photocurrent of the 
photoanodes is obtained by subtracting the dark current from that under irradiation). The IPCE values of the photoanodes were calculated using the following equation:

$$
I P C E_{\text {photoanode }}=\frac{\text { photocurrent }_{\text {photoanode }} \times I P C E_{S i}}{\text { photocurrent }_{S i}}
$$

All the measured potentials against SCE were converted to the reversible hydrogen electrode (RHE) scale according to the Nernst equation:

$$
E_{R H E}=E_{A g / A g C l}+0.059 \times p H+E_{A g / A g C l}^{0}
$$

where $E_{R H E}$ is the calculated potential versus RHE, $E_{A g / A g C l}$ is the measured potential against the saturated $\mathrm{Ag} / \mathrm{AgCl}$ electrode, and $E_{A g / A g C l}^{0}$ is the standard potential of the saturated $\mathrm{Ag} / \mathrm{AgCl}$ electrode $\left(0.197 \mathrm{~V}\right.$ at $\left.25^{\circ} \mathrm{C}\right)$. IPCE values from 300 to $600 \mathrm{~nm}$ were measured at the potential of $0.23 \mathrm{~V}$ vs. $\mathrm{Ag} / \mathrm{AgCl}(+1.23 \mathrm{~V}$ RHE using a $150 \mathrm{~W}$ Xenon lamp equipped with a monochromator (M24-D).

\section{Theoretical Calculations}

All simulations were performed using three-dimensional full-field finite difference time domain methods (Lumerical FDTD Solutions 7.5). The geometrical parameters of the sample were set to be in accordance with the experimental measurement. The cone, FC (200 nm top diameter), and pillar nanograting configurations have the same pitch $(600 \mathrm{~nm})$, height $(300 \mathrm{~nm})$, and base diameter $(440 \mathrm{~nm})$. The disordered FC sample considered has the same pitch, height and diameter (pitch $=600 \mathrm{~nm}$, height $=300 \mathrm{~nm}$, base diameter $=440 \mathrm{~nm}$, top diameter $=200 \mathrm{~nm}$ ) as the optimized experimental sample. A plane wave light source with wavelength varying in the range 300-1000 nm irradiated perpendicularly incident onto individual FCs with periodic in-plane boundary conditions. All the simulations were carried out with the electrolyte side irradiated, and the mesh accuracy set to be 3 , which was proven to be sufficiently fine in convergence tests. Electric field distribution was recorded using two-dimensional field profile monitors. The electric field density in $\alpha-\mathrm{Fe}_{2} \mathrm{O}_{3}$ layer is obtained by averaging three representative electric field intensity values in the middle and both ends of the strong electric field region inside the $\alpha-\mathrm{Fe}_{2} \mathrm{O}_{3}$. The field vectors were monitored in three-dimensional grid points to extract the absorption spectra of $\alpha-\mathrm{Fe}_{2} \mathrm{O}_{3}$ and $\mathrm{Au}$, and to generate field distribution maps at the wavelength of interest. 
The total absorbed photon number in different nanograting geometries is calculated using the following equation:

$$
N_{\text {absorbed }}=\int_{\lambda_{a}}^{\lambda_{b}} P(\lambda) A(\lambda) \frac{\lambda}{h c} d \lambda
$$

where $\lambda_{a}$ is the shortest wavelength of the absorption edge of the photoelectrode; $\lambda_{b}$ is the longest wavelength of the absorption edge of the photoelectrode; and $P, \lambda, h, c$, and $A$ are the power of incident photons, the wavelength of incident monochromatic light, the Planck constant, the speed of light, and the absorption of the photoelectrode, respectively. Light absorption in the $\alpha-\mathrm{Fe}_{2} \mathrm{O}_{3}$ and $\mathrm{Au}$ layers was calculated using the following equation:

$$
P_{a b s}=-0.5 \omega|E|^{2} \operatorname{imag}(\varepsilon)
$$

where $\omega=2 \pi / \lambda$ and $\lambda$ is the irradiation wavelength, $E$ is the electric field intensity, and $\varepsilon$ is the Au permittivity. The electric field intensity and Au permittivity were measured by a three-dimensional frequency-domain field monitor and a refractive index monitor, respectively.
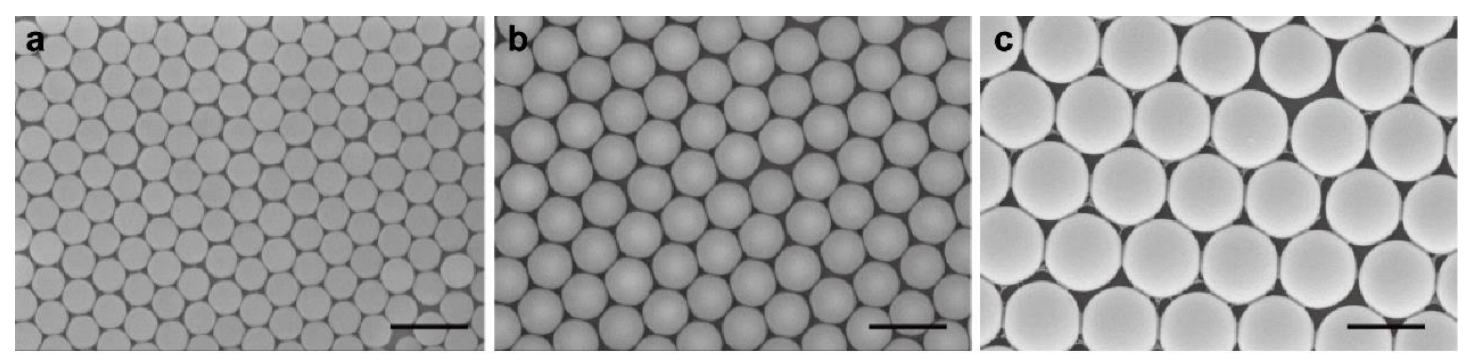

Figure S1. SEM images of monolayers of PS microspheres with different diameters of (a) $440 \mathrm{~nm}$, (b) $600 \mathrm{~nm}$, and (c) $1000 \mathrm{~nm}$. Scale bars, $500 \mathrm{~nm}$. 

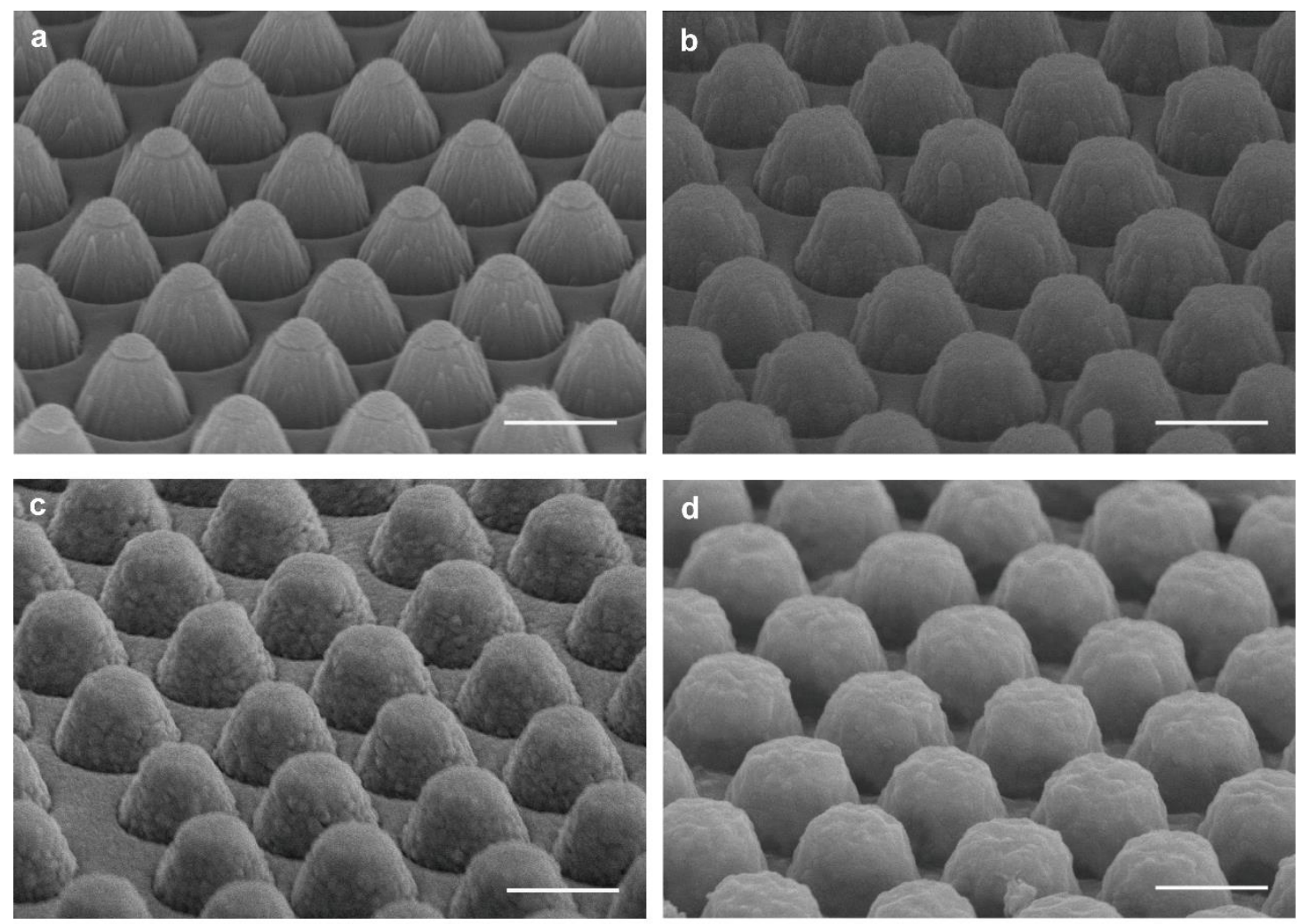

Figure S2. SEM images of the samples at different steps of the photoanode fabrication. SEM images of (a) $\mathrm{SiO}_{2} \mathrm{FC}$ nanograting with the etched PS microsphere on the top of each FC; (b) $\mathrm{SiO}_{2} \mathrm{FC}$ nanograting with a $150 \mathrm{~nm}$-thick ITO adhesion layer after washing the PS microspheres; (c) ITO-coated $\mathrm{SiO}_{2} \mathrm{FC}$ nanograting after thermally depositing a $100 \mathrm{~nm}$-thick Au film; (d) $\mathrm{SiO}_{2} / \mathrm{ITO} / \mathrm{Au} \mathrm{FC}$ nanograting with a $50 \mathrm{~nm}$-thick Fe film magnetically sputtered after annealing at high temperature. Scale bars, $500 \mathrm{~nm}$.

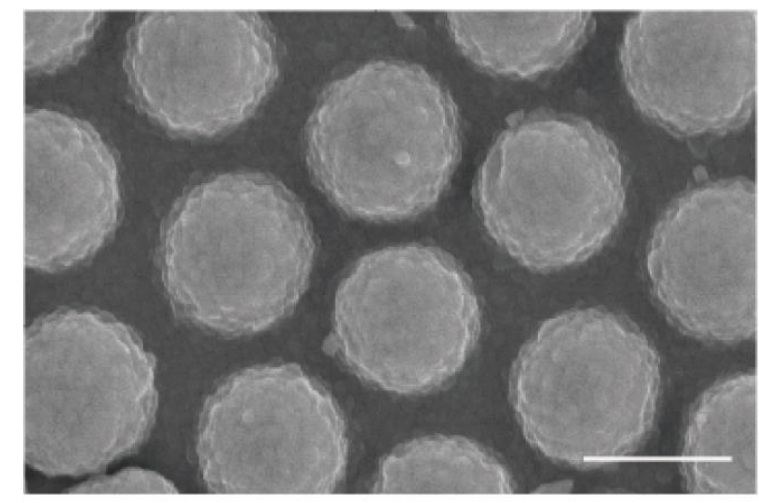

Figure S3. Top-view SEM image of the ordered $\mathrm{SiO}_{2} / \mathrm{ITO} / \mathrm{Au} / \alpha-\mathrm{Fe}_{2} \mathrm{O}_{3} \quad \mathrm{FC}$ nanograting $($ pitch $=600 \mathrm{~nm}$, height $=300 \mathrm{~nm}$, base diameter $=440 \mathrm{~nm}$, and top diameter $=200 \mathrm{~nm}$ ). The scale bar is $500 \mathrm{~nm}$. 


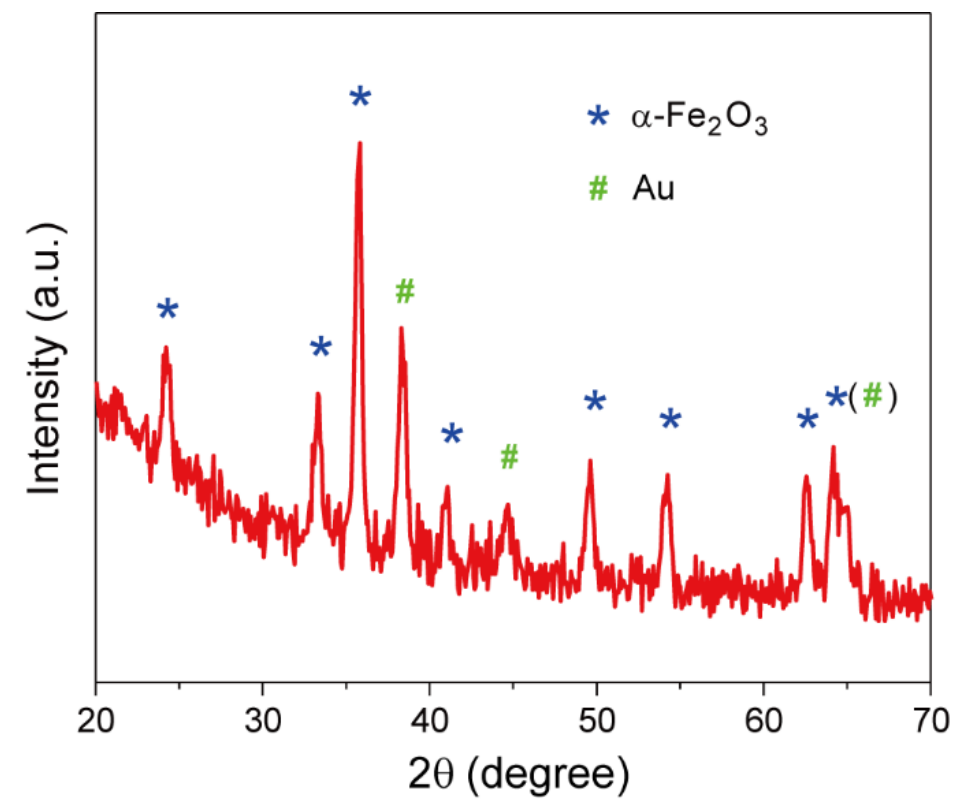

Figure $\mathrm{S4}$. XRD pattern of the as-prepared $\mathrm{SiO}_{2} / \mathrm{ITO} / \mathrm{Au} / \alpha-\mathrm{Fe}_{2} \mathrm{O}_{3}$ anode with the $\mathrm{FC}$ nanograting structure.

The X-ray diffraction (XRD) pattern in Figure S4 shows characteristic peaks corresponding to diffraction from the (012), (104), (110), (113), (024), (116), (214), and (300) planes of $\alpha-\mathrm{Fe}_{2} \mathrm{O}_{3}$ (PDF \# 33-0664), indicating complete conversion from Fe to $\alpha-\mathrm{Fe}_{2} \mathrm{O}_{3}$; (111), (200), and (220) peaks for $\mathrm{Au}$ (PDF \# 04-0784) are also detected, confirming the successful deposition of the Au film. 

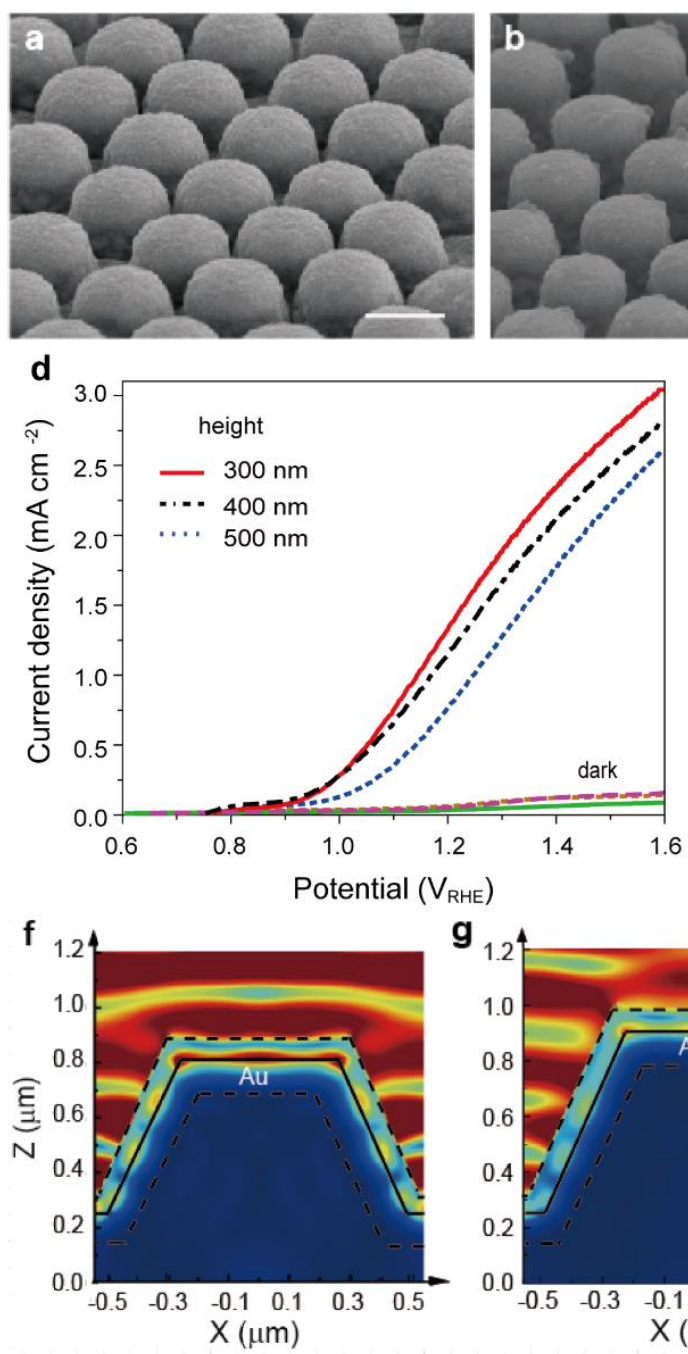
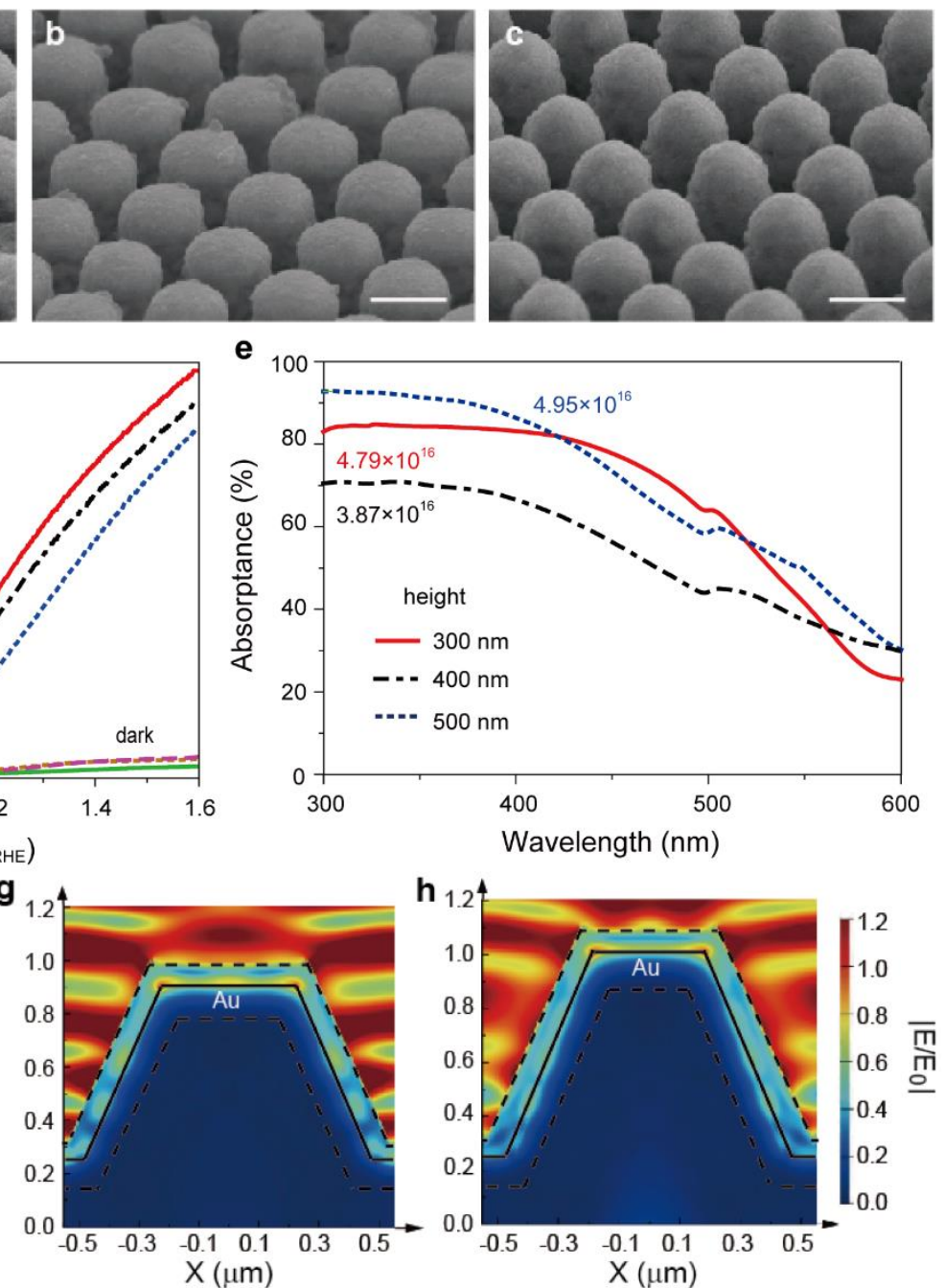

Figure S5. $\mathrm{SiO}_{2} / \mathrm{ITO} / \mathrm{Au} / \alpha-\mathrm{Fe}_{2} \mathrm{O}_{3}$ FC nanogratings with different heights. SEM images of $\mathrm{SiO}_{2} / \mathrm{ITO} / \mathrm{Au} / \alpha-\mathrm{Fe}_{2} \mathrm{O}_{3} \mathrm{FC}$ nanogratings with different heights, (a) $300 \mathrm{~nm}$, (b) $400 \mathrm{~nm}$, and (c) $500 \mathrm{~nm}$. Scale bars, $500 \mathrm{~nm}$. (d) Photocurrent and dark current densities of $\mathrm{SiO}_{2} / \mathrm{ITO} / \mathrm{Au} / \alpha-\mathrm{Fe}_{2} \mathrm{O}_{3} \mathrm{FC}$ nanogratings of different heights. (e) FDTD simulated absorption curves of a- $\mathrm{Fe}_{2} \mathrm{O}_{3}$ in $\mathrm{SiO}_{2} / \mathrm{ITO} / \mathrm{Au} / \alpha-\mathrm{Fe}_{2} \mathrm{O}_{3}$ FCs with different heights $(300,400$, and $500 \mathrm{~nm})$. The total absorbed photon number in $300-600 \mathrm{~nm}$ is labeled on the corresponding curve, respectively. FDTD-simulated electric field distribution $\left|\mathrm{E} / \mathrm{E}_{0}\right|$ of $\mathrm{SiO}_{2} / \mathrm{ITO} / \mathrm{Au} / \alpha-\mathrm{Fe}_{2} \mathrm{O}_{3} \mathrm{FCs}$ with different heights, (f) $300 \mathrm{~nm},(\mathrm{~g}$ ) $400 \mathrm{~nm}$, and (h) $500 \mathrm{~nm}$ at the wavelength of $516 \mathrm{~nm}$. 
First, the changes of the photocurrent, absorption, FDTD-simulated electric field intensity of the $\mathrm{SiO}_{2} / \mathrm{ITO} / \mathrm{Au} / \alpha-\mathrm{Fe}_{2} \mathrm{O}_{3}$ anode with the different $\mathrm{FC}$ nanograting heights $(300,400$, and $500 \mathrm{~nm})$ and the same pitch $(600 \mathrm{~nm})$ and base diameter (440 $\mathrm{nm}$ ) were studied (Figure S5a-c). The photocurrent density of $\mathrm{SiO}_{2} / \mathrm{ITO} / \mathrm{Au} / \alpha-\mathrm{Fe}_{2} \mathrm{O}_{3}$ decreases in the whole tested potential range when the height increases (Figure $\mathbf{S} 5 \mathrm{~d}$ ). In contrast, light absorption of a- $\mathrm{Fe}_{2} \mathrm{O}_{3}$ increases with increasing height (Figure $\mathbf{S} 5 \mathrm{e}$, Table 1), implying that light absorption is not the main reason for the photocurrent decrease. The electric field intensity in $\alpha-\mathrm{Fe}_{2} \mathrm{O}_{3}$ near the $\mathrm{Au} / \alpha-\mathrm{Fe}_{2} \mathrm{O}_{3}$ interface decreases with increasing height (Figure $\mathbf{S} 5 \mathrm{f}-\mathrm{h}$ ), which is in accordance with the experimentally observed changing trend in photocurrent density, indicating the electric field intensity is closely related to the anode activity (Table 1).
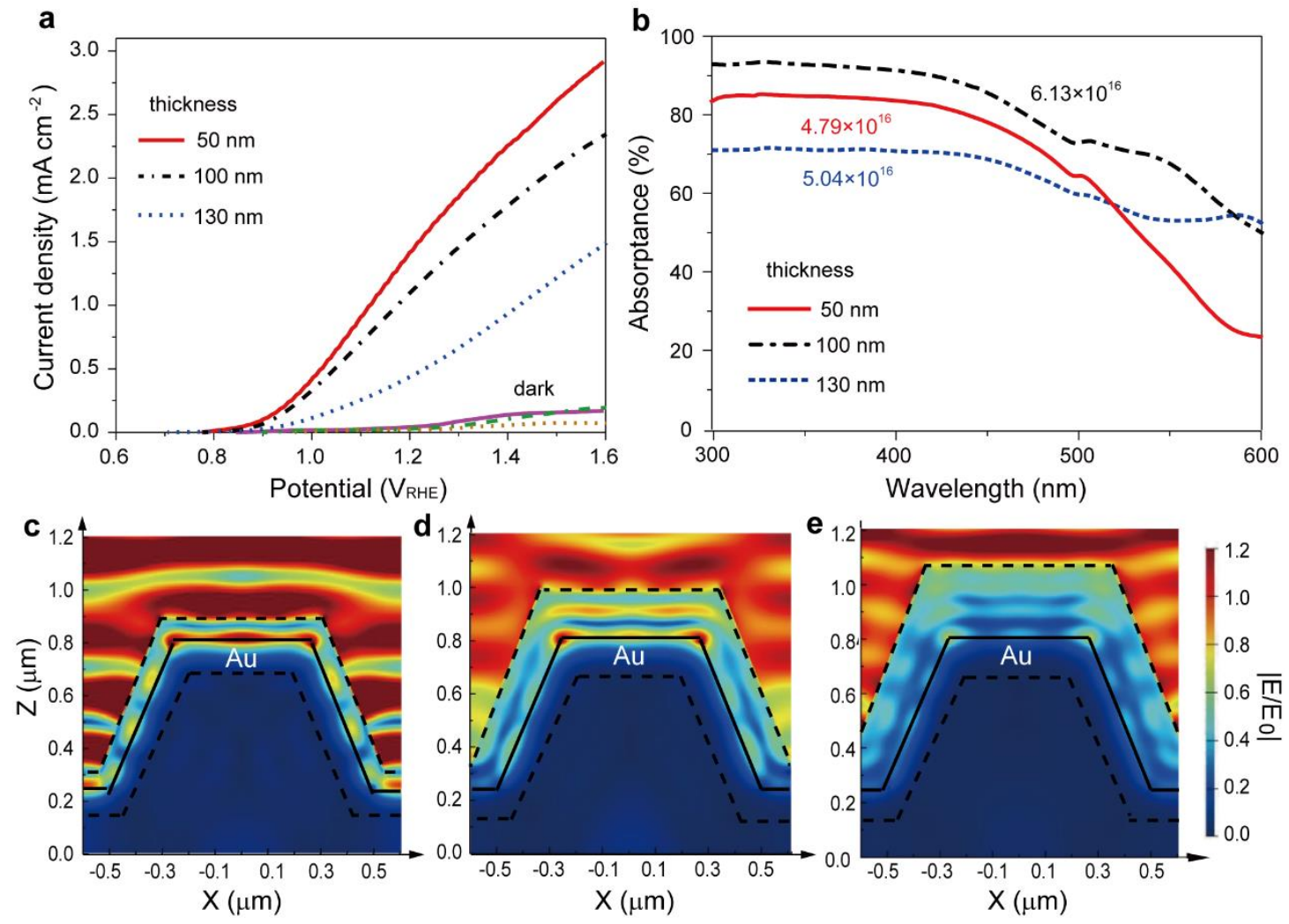

Figure S6. $\mathrm{SiO}_{2} / \mathrm{ITO} / \mathrm{Au} / \alpha-\mathrm{Fe}_{2} \mathrm{O}_{3} \mathrm{FC}$ nanogratings with different $\alpha-\mathrm{Fe}_{2} \mathrm{O}_{3}$ thicknesses.

(a) Photocurrent and dark current densities of $\mathrm{SiO}_{2} / \mathrm{ITO} / \mathrm{Au} / \alpha-\mathrm{Fe}_{2} \mathrm{O}_{3} \mathrm{FC}$ nanogratings with different $\alpha-\mathrm{Fe}_{2} \mathrm{O}_{3}$ thicknesses. (b) FDTD simulated absorption curves of $\alpha-\mathrm{Fe}_{2} \mathrm{O}_{3}$ in $\mathrm{SiO}_{2} / \mathrm{ITO} / \mathrm{Au} / \alpha-\mathrm{Fe}_{2} \mathrm{O}_{3} \mathrm{FCs}$ with different thicknesses $(50,100$, and $130 \mathrm{~nm})$. The 
total absorbed photon number in $300-600 \mathrm{~nm}$ is labeled on the corresponding curve, respectively. FDTD-simulated electric field distribution $\left|\mathrm{E} / \mathrm{E}_{0}\right|$ of $\mathrm{SiO}_{2} / \mathrm{ITO} / \mathrm{Au} / \alpha-\mathrm{Fe}_{2} \mathrm{O}_{3} \mathrm{FCs}$ with different $\alpha-\mathrm{Fe}_{2} \mathrm{O}_{3}$ thicknesses, (c) $50 \mathrm{~nm}$, (d) $100 \mathrm{~nm}$, and (e) $130 \mathrm{~nm}$ at the wavelength of $516 \mathrm{~nm}$.

Due to the subwavelength thickness of the $\alpha-\mathrm{Fe}_{2} \mathrm{O}_{3}$ layer, the effective refractive index is averaged over the $\alpha-\mathrm{Fe}_{2} \mathrm{O}_{3}$ layer and the electrolyte. ${ }^{1-3}$ So we change the $\alpha-\mathrm{Fe}_{2} \mathrm{O}_{3}$ layer thickness to adjust the effective refractive index to get better SPP. With increasing $\alpha-\mathrm{Fe}_{2} \mathrm{O}_{3}$ layer thickness $(50 \mathrm{~nm}, 100 \mathrm{~nm}$, and $130 \mathrm{~nm}$ ), the photocurrent density reduces gradually (Figure S7a). As shown in Figure S7b, the FC nanograting with the $\alpha-\mathrm{Fe}_{2} \mathrm{O}_{3}$ thickness of $100 \mathrm{~nm}$ obtains the maximum total absorbed photon number in a-Fe $\mathrm{O}_{3}$ by FDTD simulation at the wavelength range of 300-600 nm, meaning the maximum light absorption in $\mathrm{a}-\mathrm{Fe}_{2} \mathrm{O}_{3}$. Thus, the activity change with thickness cannot be explained by change of absorption (Figure S7b, Table 1). In contrast, the electric field in the $\alpha-\mathrm{Fe}_{2} \mathrm{O}_{3}$ layer decreases with $\alpha-\mathrm{Fe}_{2} \mathrm{O}_{3}$ thickness (Figure S7c-e), which is in accordance with the changing trend in the photocurrent density. 

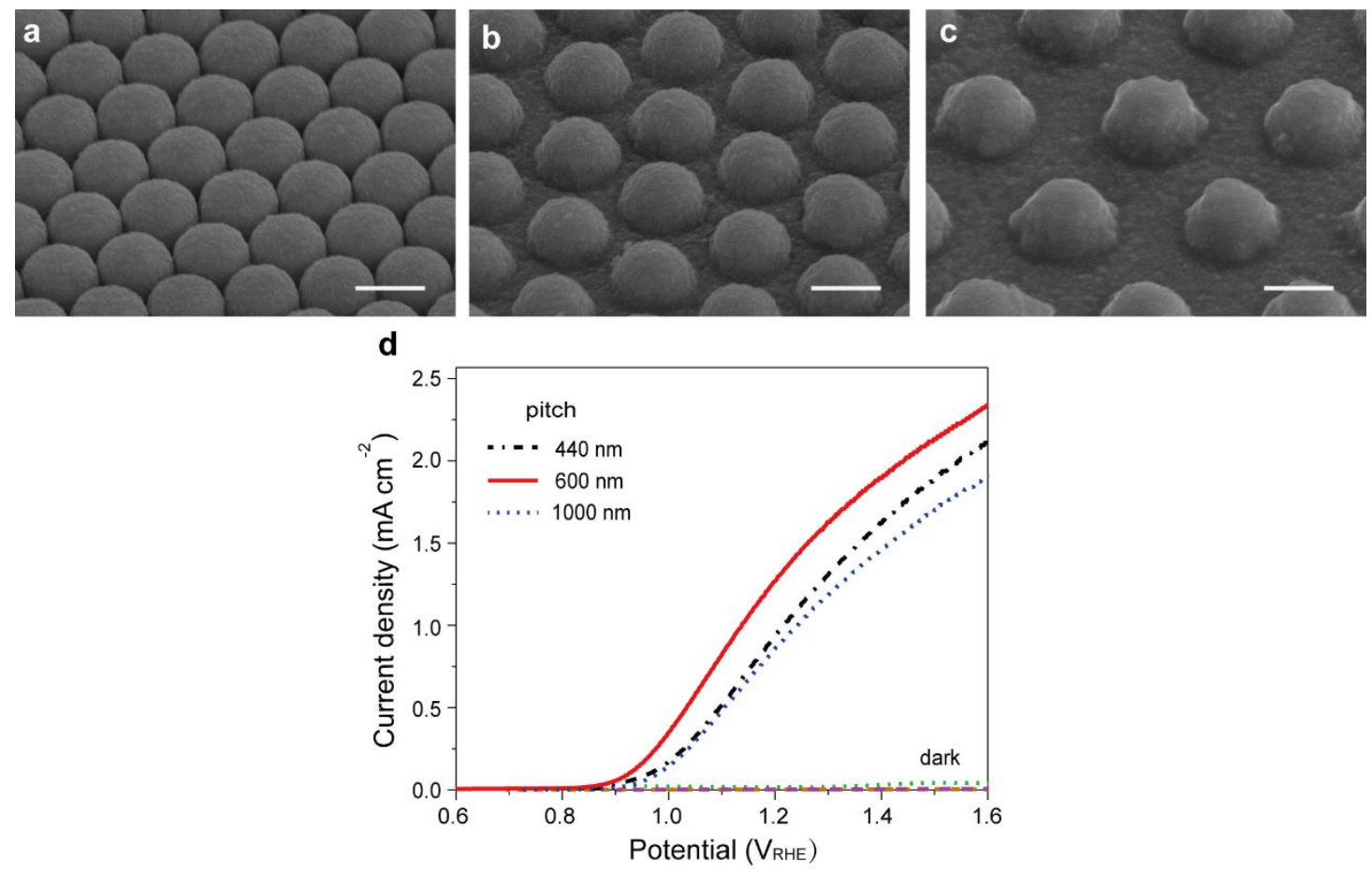

Figure S7. $\mathrm{SiO}_{2} / \mathrm{ITO} / \mathrm{Au} / \alpha-\mathrm{Fe}_{2} \mathrm{O}_{3} \quad \mathrm{FC}$ nanogratings with different pitches. SEM images of the $\mathrm{SiO}_{2} / \mathrm{ITO} / \mathrm{Au} / \alpha-\mathrm{Fe}_{2} \mathrm{O}_{3} \mathrm{FC}$ nanogratings with different pitches, (a) 440 $\mathrm{nm}$, (b) $600 \mathrm{~nm}$, and (c) $1000 \mathrm{~nm}$. The scale bars, $500 \mathrm{~nm}$. (d) Photocurrent and dark current densities of $\mathrm{SiO}_{2} / \mathrm{ITO} / \mathrm{Au} / \alpha-\mathrm{Fe}_{2} \mathrm{O}_{3} \mathrm{FC}$ nanogratings with different pitches (440, 600, and $1000 \mathrm{~nm})$.

We also optimized for the pitch (440, 600, and $1000 \mathrm{~nm}$ ) of the FC nanograting for the better activity of the photoanodes, with all other parameters remaining the same (Figure S7a-c). The maximum photocurrent density of $\sim 1.33 \mathrm{~mA} \mathrm{~cm}^{-2}$ at the bias of $1.23 \mathrm{~V}_{\mathrm{RHE}}$ is obtained when the pitch of the FC nanograting is $600 \mathrm{~nm}$ (Figure $\mathbf{S} 7 \mathrm{~d}$ ). We did not do the FDTD simulation for different pitched, because our simulation conditions cannot meet such a large calculating requirement. 

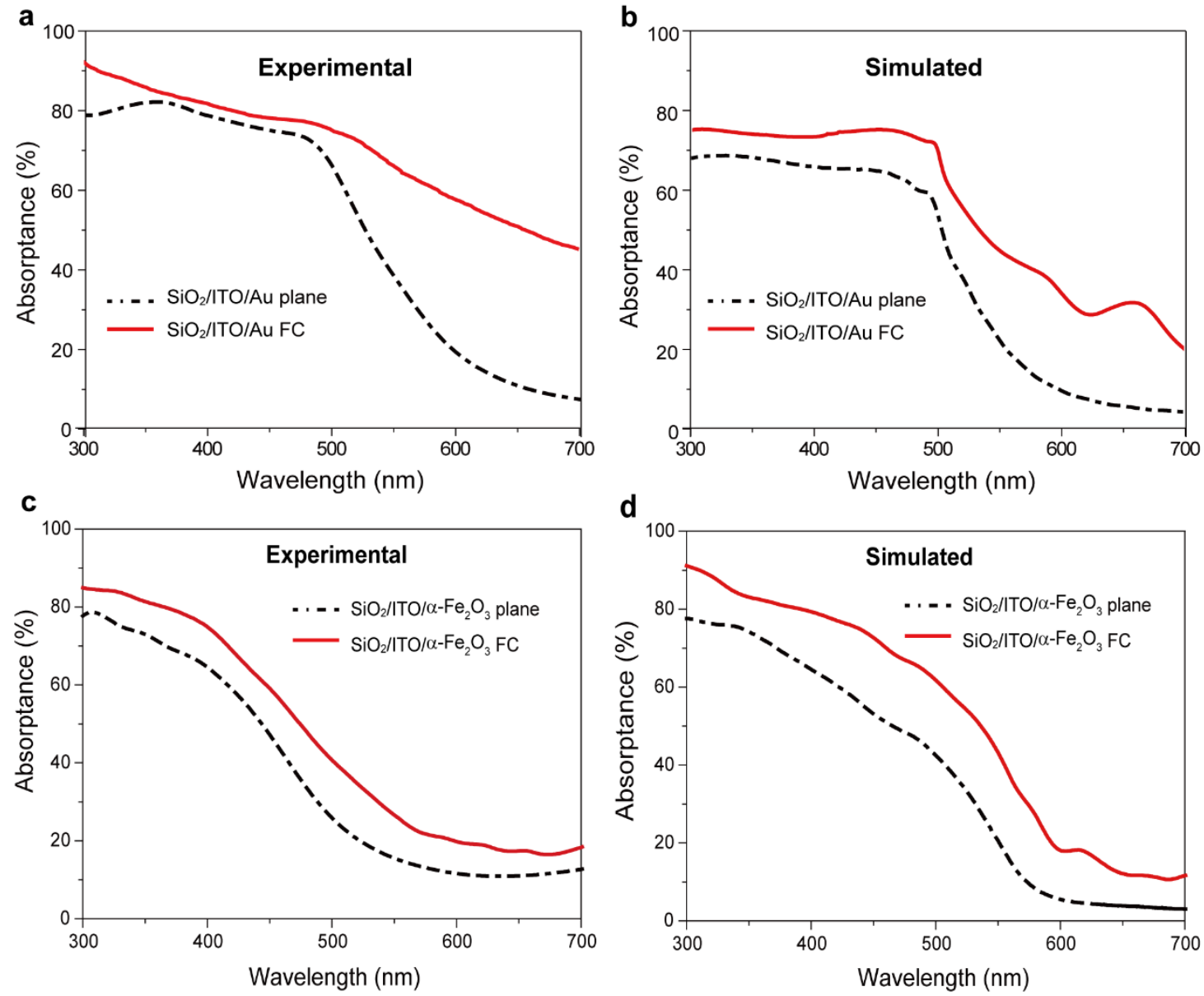

Figure S8 . Light absorption spectra of $\mathrm{SiO}_{2} / \mathrm{ITO} / \mathrm{Au}$ and $\mathrm{SiO}_{2} / \mathrm{ITO} / \alpha-\mathrm{Fe}_{2} \mathrm{O}_{3} \quad \mathrm{FC}$ nanograting and planar structures. (a) Experimental and (b) simulated light absorption spectra of $\mathrm{SiO}_{2} / \mathrm{ITO} / \mathrm{Au} \mathrm{FC}$ nanograting $($ pitch $=600 \mathrm{~nm}$, height $=300 \mathrm{~nm}$, base diameter $=440 \mathrm{~nm}$, and top diameter $=200 \mathrm{~nm}$ ) and planar structures. (c) Experimental and (d) simulated light absorption spectra of $\mathrm{SiO}_{2} / \mathrm{ITO} / \alpha-\mathrm{Fe}_{2} \mathrm{O}_{3} \quad \mathrm{FC}$ nanograting (pitch $=600 \mathrm{~nm}$, height $=300 \mathrm{~nm}$, base diameter $=440 \mathrm{~nm}$, and top diameter $=200 \mathrm{~nm}$ ) and planar structures. 


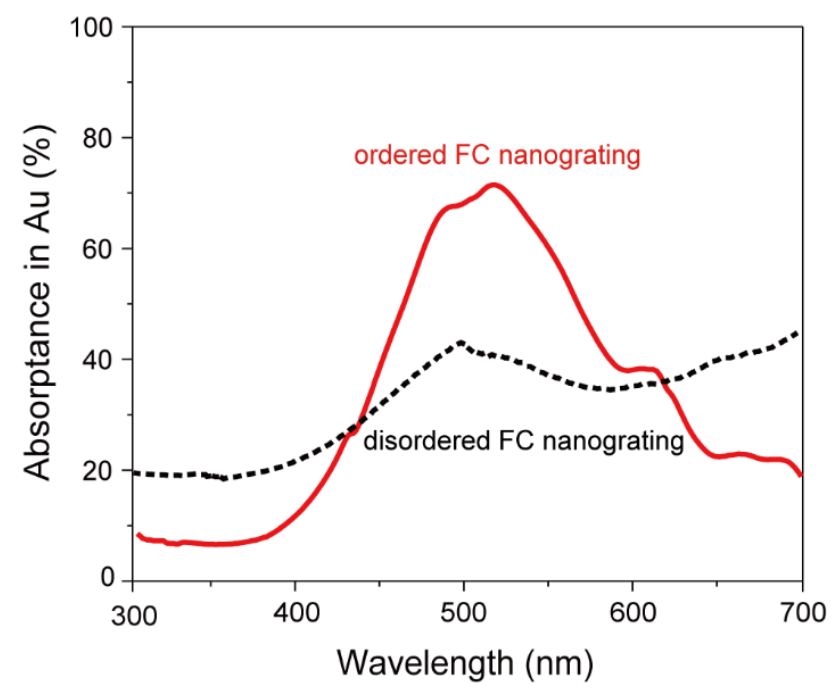

Figure S9 . FDTD simulated absorption curves of $\mathrm{Au}$ in the ordered and disordered FC nanogratings of $\mathrm{SiO}_{2} / \mathrm{ITO} / \mathrm{Au} / \alpha-\mathrm{Fe}_{2} \mathrm{O}_{3}$.

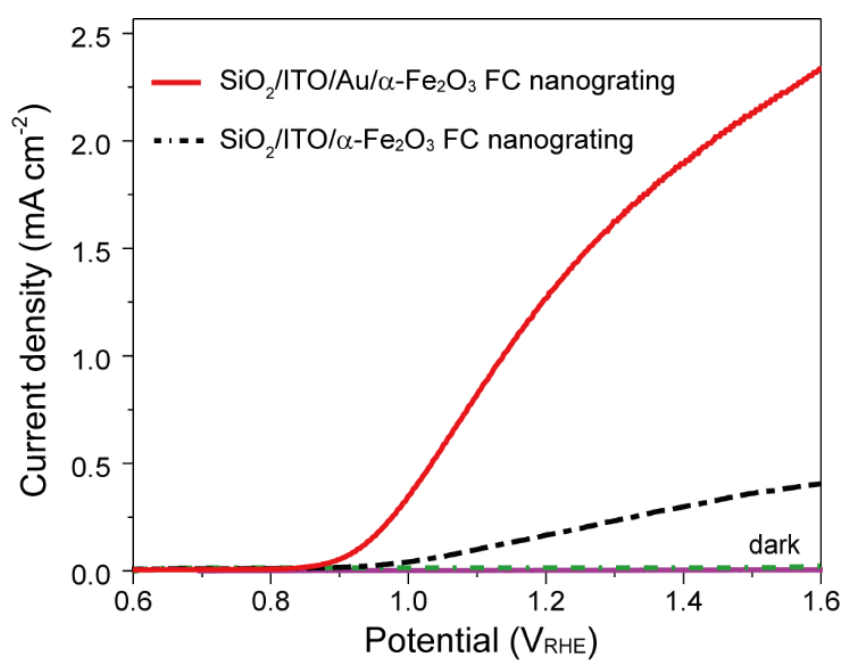

Figure S10. Photocurrent and dark current densities of $\mathrm{SiO}_{2} / \mathrm{ITO} / \mathrm{Au} / \alpha-\mathrm{Fe}_{2} \mathrm{O}_{3}$ and $\mathrm{SiO}_{2} / \mathrm{ITO} / \alpha-\mathrm{Fe}_{2} \mathrm{O}_{3}$ (without $\mathrm{Au}$ ) $\mathrm{FC}$ nanograting structures. 
Table S1. Comparison of PEC OER of the $\mathrm{Au} / \mathrm{Fe}_{2} \mathrm{O}_{3}$ Based Photoanodes.

\begin{tabular}{|c|c|c|c|c|}
\hline Photoanode & $\begin{array}{l}\text { Mechanism } \\
\text { of plasmon }\end{array}$ & Electrolyte & $\begin{array}{l}\text { Maximum } \\
\text { relative IPCE }\end{array}$ & Reference \\
\hline $\begin{array}{l}\mathrm{SiO}_{2} / \mathrm{ITO} / \mathrm{Au} \\
/ \mathrm{Fe}_{2} \mathrm{O}_{3} \mathrm{FC} \\
\text { nanograting }\end{array}$ & $\begin{array}{l}\text { SPP-induced } \\
\text { electric field }\end{array}$ & $1 \mathrm{M} \mathrm{NaOH}$ & 110 & our work \\
\hline $\begin{array}{l}\mathrm{Fe}_{2} \mathrm{O}_{3} \\
\text { electrodes } \\
\text { on } \mathrm{Au} \\
\text { nanopillar } \\
\text { array }\end{array}$ & $\begin{array}{l}\text { SPR light } \\
\text { absorption }\end{array}$ & $1 \mathrm{M} \mathrm{NaOH}$ & 4 & 5 \\
\hline $\begin{array}{l}\mathrm{Au} / \mathrm{Fe}_{2} \mathrm{O}_{3} \\
\text { nanoplates }\end{array}$ & $\begin{array}{l}\text { LSPR hot } \\
\text { electron injection }\end{array}$ & $1 \mathrm{M} \mathrm{KOH}$ & 2.5 & 6 \\
\hline $\begin{array}{l}\mathrm{Fe}_{2} \mathrm{O}_{3} \text { on } \\
\mathrm{SiO}_{2} / \mathrm{Au} / \mathrm{Ti} \\
\text { nanohole } \\
\text { array }\end{array}$ & $\begin{array}{l}\text { SPP guided } \\
\text { mode, increasing } \\
\text { absorption; } \\
\text { LSPR increased } \\
\text { absorption }\end{array}$ & $1 \mathrm{M} \mathrm{NaOH}$ & 18 & 7 \\
\hline $\begin{array}{l}\mathrm{Fe}_{2} \mathrm{O}_{3} \text { film } \\
\text { embedded } \\
\text { with } \mathrm{Au} \\
\text { nanoparticles }\end{array}$ & $\begin{array}{l}\text { LSPR increased } \\
\text { Light absorption }\end{array}$ & $0.5 \mathrm{M} \mathrm{NaOH}$ & 2 & 8 \\
\hline
\end{tabular}

a The incident photon-to-current efficiency.

Table S1 lists a literature survey of some representative publications of the $\mathrm{Au} / \mathrm{Fe}_{2} \mathrm{O}_{3}$ based photoanodes for the plasmonic enhancement of the PEC OER. The relative IPCE of the sample was used for the performance comparison since it can accurately display the plasmonic effect. The relative IPCE value of our sample shows a dramatic $\sim 110$-fold increase at $516 \mathrm{~nm}$. In contrast, no more than 20 -fold increase was reported in the related works. That is, our relative IPCE value is about 6-55 times higher than those reported for the $\mathrm{Au} / \mathrm{Fe}_{2} \mathrm{O}_{3}$ based photoanodes. demonstrating the highest enhancement factor reported so far. 


\section{References}

(1) Zhang, J.; Chen, Z.; Wang, Z.; Zhang, W.; Ming, N. Mater. Lett. 2003, 57, (28), 4466-4470.

(2) Gao, H.; Liu, C.; Jeong, H. E.; Yang, P. ACS Nano 2012, 6, (1), 234-240.

(3) Raether, H. Springer Tracts in Modern Physics 1988, 111, 1-133.

(4) Chien, F. C.; Chen, S. J. Opt. Lett. 2006, 31, (2), 187-189.

(5) Gao, H.; Liu, C.; Jeong, H. E.; Yang, P. ACS Nano 2012, 6, (1), 234-240.

(6) Lei, F.; Liu, H.; Yu, J.; Tang, Z.; Xie, J.; Hao, P.; Cui, G.; Tang, B. Phys. Chem. Chem. Phys. 2019, 21, (3), 1478-1483

(7) Li, J.; Cushing, S. K.; Zheng, P.; Meng, F.; Chu, D.; Wu, N. Nat. Commun. 2013, 4, 2651-2658.

(8) Archana, P. S.; Pachauri, N.; Shan, Z. C.; Pan, S. L.; Gupta, A. J. Phys. Chem. C 2015, 119, (27), 15506-15516. 